\title{
Manajemen Persediaan dan Layout Gudang di Teknik Perawatan Pesawat Udara Politeknik Negeri Batam dalam Tinjauan Project-Based Learning
}

\section{Inventory Management and Warehouse Layout in Aircraft Maintenance Engineering, Politeknik Negeri Batam in Project-Based Learning Review}

\section{Sugeng Riadi ${ }^{1}$, Fandy Bestario Harlan² Riri Zelmiyanti ${ }^{3}$ Shinta Wahyu Hati ${ }^{4}$ Adhitomo Wirawan 5}

\author{
${ }^{1}$ Akuntansi Manajerial - Politeknik Negeri Batam \\ 2Logistik dan Perdagangan Internasional - Politeknik Negeri Batam \\ ${ }^{3}$ Akuntansi Manajerial - Politeknik Negeri Batam \\ 4Logistik dan Perdagangan Internasional- Politeknik Negeri Batam \\ ${ }^{5}$ Administrasi Bisnis Terapan - Politeknik Negeri Batam \\ Email: sugeng@polibatam.ac.id
}

\begin{abstract}
ABSTRAK
Pencatatan persediaan menjadi sangat penting bagi perusahaan atau institusi untuk mengetahui keluar masuk barang atau persediaan. Tujuan penelitian ini adalah untuk memberikan perbaikan manajemen persediaan dan memberikan rancangan layout gudang di Teknik Perawatan Pesawat Udara (TPPU) Politeknik Negeri Batam dengan tinjauan Project-Based Learning. Penelitian ini merupakan applied research dengan pendekatan deskriptif eksploratif. Penelitian merupakan penerapan project-based learning dengan matakuliah Akuntansi Keuangan Dasar II dan Pergudangaan \& Persediaan antara Program Studi Akuntansi Manajerial dan Logistik \& Perdagangan Internasional. Hasil penelitian ini berisi hasil perbaikan manajemen persediaan (update stock opname dan pencatatan), rancangan material request form, issue request list, inventory stock card dan rancangan layout gudang.
\end{abstract}

Kata Kunci: layout gudang, manajemen persediaan, project-based learning

\begin{abstract}
Inventory recording becomes very important for companies or institutions to know in and out of goods or supplies. The purpose of this research is to provide inventory management improvements and provide warehouse layout design at Aircraft Maintenance Engineering, Politeknik Negeri Batam with Project-Based Learning review. This research is applied research with an exploratory descriptive approach. The Research is the application of project-based learning with basic financial accounting II and trade \& inventory between managerial accounting and logistics \& international trade study programs. The results of this study contain the results of inventory management improvements (stock opname updates and records), material request form design, issue request list, inventory stock card and warehouse layout design.
\end{abstract}

Keywords: warehouse layout, inventory management, project-based learning

Hal. 7 


\section{PENDAHULUAN}

Pencatatan persediaan menjadi sangat penting bagi perusahaan atau institusi untuk mengetahui keluar masuk barang atau persediaan. Manajemen yang baik akan menghasilkan pencatatan baik dari segi harga pembeliannya, persediaan akhirnya, kondisi barang hingga penyusutan atau depresiasinya. Saat pencatatan persediaan tidak baik, maka akan timbul permasalahan seperti tidak terkontrolnya alur keluar masuk barang, kelebihan stok maupun kekurangan yang menggangu kelancaran operasional dan kemungkinan barang hilang di gudang.

Manajemen persediaan sangat diperlukan dalam organisasi, karena manajemen persediaan menyangkut bagaimana organisasi dapat mengendalikan persediaan yang dimiliki baik dari sisi pemesanan barang, penerimaan barang, penyimpanan, pemeliharaan dan pemakaian. Dalam pelaksanaan pengelolaan persediaan diperlukan sistem dan standar operasional prosedur yang menggambarkan pengendalian internal, sehingga organisasi dapat menjalankan aktivitasnya dengan baik.

Saat ini Jurusan Teknik Perawatan Pesawat Udara (TPPU) Politeknik Negeri Batam belum memiliki manajemen persediaan yang baik. Hal ini dapat dilihat bahwa kondisi persediaan (bahan habis pakai (BHP), peralatan (tools) dan hasil karya praktikum mahasiswa tidak tercatat dengan baik. Persediaan bahan habis pakai tidak sesuai antara barang tercatat dengan kondisi fisik barang yang ada di gudang. Begitupun dengan peralatan (tools) yang dipakai untuk kegiatan praktikum mahasiswa. Dengan kondisi tersebut, sangat rentan terhadap hilangnya beberapa peralatan, tidak terkontrolnya persediaan bahan habis pakai serta hasil karya mahasiswa yang tidak diinventarisir dengan baik.

Untuk mengelola persediaan tersebut diperlukan inventory stock, dimana Jurusan Teknik Perawatan Pesawat Udara (TPPU) belum memiliki hal tersebut. Inventory stock bagi organisasi dapat berfungsi mengontrol dengan pencatatan keluar masuk barang. Sehingga saldo pencatatan persediaan akan sesuai dengan kondisi fisik di gudang. Selain belum optimalnya manajemen persediaan di TPPU, kondisi gudang belum memiliki layout atau tata letak barang yang baik. Persediaan bahan habis pakai dan peralatan belum tersusun rapi sesuai dengan jenis dan kode barang. Barang di gudang juga bercampur dengan barang dalam bentuk cair atau berbahaya. Beberapa hasil karya praktikum mahasiswa juga belum disusun ditempatnya. Berdasarkan permasalahan yang terjadi, penulis akan melakukan penelitian yang melibatkan mahasiswa, dimana mahasiswa tersebut melakukan project-based learning di Jurusan Teknik Perawatan Pesawat Udara (TPPU). Berdasarkan latar belakang yang penulis paparkan maka, peneliti mengambil topik yaitu Manajemen Persediaan dan Layout Gudang di Teknik Perawatan Pesawat Udara Politeknik Negeri Batam Dalam Tinjauan Project-Based Learning

\section{LANDASAN TEORI}

\section{Manajemen Persediaan}

Persediaan merupakan sebuah perlengkapan untuk mendukung operasional instansi, yang disediaakan oleh bagian tertentu untuk digunakan saat dibutuhkan (Tyoso, 2016). Menurut PSAK 14 (revisi 2008) dalam buku Martani et al (2016) mendefinisikan persediaan sebagai asset yang tersedia untuk dijual dalam kegiatan usaha biasa, dalam proses produksi untuk penjualan tersebut, dalam bentuk bahan atau perlengkapan untuk digunakan dalam proses produksi atau pemberian jasa. Sedangkan menurut Purwaji et al (2016) persediaan merupakan salah satu jenis 
aset lancar yang jumlahnya relatif besar di dalam suatu perusahaan dagang, jasa, maupun manufaktur. Hal ini karena persediaan merupakan salah satu faktor penting yang menentukan kelancaran operasional perusahaan.

Yang harus diperhatikan dalam manajemen persediaan adalah:

1. Waktu kedatangan barang yang akan dipesan kembali. Jika waktu barang yang dipesan cukup lama pada periode tertentu maka persediaan barang tersebut harus disesuaikan hingga barang tersebut ada setiap saat hingga barang yang dipesan selanjutnya ada.

2. Berapa kuantitas jumlah barang yang akan disimpan. Jumlah kuantitas barang yang dipesan harus disesuaikan karena jika terlalu banyak akan terjadi pemborosan namun jika terlalu sedikit akan menimbulkan terhenti proses produksi.

3. Perhatikan juga safety stock atau persediaan pengamanan yaitu persediaan untuk antisipasi (buffer) jika terjadi sesuatu hal yang menghambat terjadinya waktu pembelian sehingga stock barang persediaan masih ada untuk beberapa waktu ke depan.

\section{Layout Gudang (Warehouse Layout)}

Gudang adalah bangunan yang digunakan untuk menyimpan barang. Barang-barang tersebut berupa bahan baku, suku cadang, barang dalam proses, dan barang jadi. Gudang tidak hanya dijadikan sebagai tempat penyimpanan, melainkan tempat penerimaan barang, pencatatan, penyimpanan, pemilihan, penyortiran, pelabelan, sampai dengan proses pengiriman. Tata letak gudang (warehouse layout) adalah suatu perancangan atau penataan susunan gudang untuk menemukan titik optimal di antara biaya penanganan bahan dan biaya-biaya yang berkaitan dengan luas ruang dalam gudang. Tata letak gudang harus dirancang dengan memperhitungkan kecepatan gerak barang. Barang yang bergerak cepat lebih baik diletakkan dekat dengan tempat pengambilan barang, sehingga mengurangi seringnya gerakan bolak-balik. Dalam gudang penyimpanan faktor yang berpengaruh sangat besar terhadap penanganan barang ialah letak dan desain gedung dimana barang itu disimpan.

Terdapat empat kebijakan yang kerap kali digunakan dalam penataan barang di gudang. Pertama, dedicated storage (fixed storage) yang menggunakan lokasi penyimpanan secara spresifik untuk barang tertentu dan tetap. Dengan penyimpanan multi produk, daerah penyimpanan yang dibutuhkan adalah jumlah kebutuhan penyimpanan maksimum untuk tiap produk. Kedua, randomized storage location (floating lot storage), penyimpanan ini memungkinkan produk yang disimpan berpindah lokasi penyimpanannya setiap saat. Penempatan barang hanya memerhatikan jarak terdekat menuju tempat penyimpanan dengan menggunakan sistem first in-first out. (FIFO). Ketiga, class-based storage (CBS) yang membagi menjadi tiga kelas berdasarkan hukum Pareto dengan memerhatikan aktivitas storage dan retrieval (S/R) dalam gudang. $80 \%$ aktivitas dalam gudang akan diberikan pada $20 \%$ item, $15 \%$ aktivitas akan diberikan pada $30 \%$ item, dan 5\% aktivitas akan diberikan pada $50 \%$ item. Keempat, shared storage, dimana beberapa produk akan menempati suatu wilayah penyimpanan yang sama

\section{Project-Based Learning (PBL)}

Pembelajaran berbasis proyek (PBL) merupakan penerapan dari pembelajaran aktif. Secara sederhana pembelajaran berbasis proyek didefinisikan sebagai suatu pengajaran yang mencoba mengaitkan antara teknologi dengan masalah kehidupan sehari-hari yang akrab dengan siswa, atau dengan proyek. Dalam pembelajaran berbasis proyek, peserta didik terdorong lebih aktif dalam belajar. Dosen hanya sebagai fasilitator, mengevaluasi produk hasil kerja peserta didik 
yang ditampikan dalam hasil proyek yang dikerjakan, sehingga menghasilkan produk nyata yang dapat mendorong kreativitas mahasiswa agar mampu berpikir kritis. Pembelajaran PBL secara umum memiliki pedoman langkah: planning (perencanaan), creating (mencipta atau implementasi) dan processing (pengolahan) (Munandar, 2009 dalam Titu, 2015). 2015):

Keuntungan model pembelajaran Project-Based Learning adalah sebagai berikut (Titu,

1. Meningkatkan motivasi belajar siswa

2. Meningkatkan kemampuan pemecahan masalah.

3. Meningkatkan kolaborasi. Pentingnya kerja kelompok dalam proyek memerlukan siswa mengembangkan dan mempraktikkan keterampilan komunikasi

4. Meningkatkan keterampilan mengelola sumber

\section{METODOLOGI PENELITIAN}

\section{Jenis dan Desain Penelitian}

Jenis penelitian ini adalah penelitian terapan (applied research) dimana peneliti berfokus pada permasalahan nyata yang terjadi di Jurusan Teknik Perawatan Pesawat Udara, dimana belum adanya manajemen persediaan, pencatatan peralataan dan layout gudang. Penelitian ini menggunakan metode kualitatif dengan klasifikasi penelitian eksploratif dan deskriptif. Penelitian eksploratif bertujuan untuk menyelidiki suatu masalah/problem untuk mendapatkan pemahaman dan pengetahuan, sedang deskriptif bertujuan untuk menggambarkan sesuatu (Malhotra, 2007).

\section{Populasi dan Sampel Penelitian}

Penelitian dilakukan di Jurusan Teknik Perawatan Pesawat Udara (TPPU), Politeknik Negeri Batam. Sedangkan sampel penelitian di bagian persediaan dan gudang di Jurusan TPPU, Politeknik Negeri Batam.

\section{Jenis Sumber Data}

Sumber data yang digunakan adalah data primer dan data sekunder. Data primer berasal dari hasil wawancara dengan bagian persediaan Jurusan TPPU, Politeknik Negeri Batam. Sedangkan data sekunder berupa data awal persediaan habis pakai, data peralataan dan kajian literatur yang berhubungan dengan penelitian ini.

\section{Metode Pengambilan Data}

Metode pengumpulan data penelitian ini adalah dengan wawancara secara langsung kepada narasumber. Selain itu peneliti juga melakukan pengamatan langsung di lapangan dan mengumpulkan data yang diperlukan dari sumber data utama.

\section{Metode Pengolahan dan Analisis Data}

Setelah data dikumpulkan, maka langkah selanjutnya menganalisis data dengan perhitungan dan pencatatan persediaan di Microsoft Excel. Selanjutnya pencatatan persediaan dianalisis menggunakan metode dan berbagai pendekatan sesuai kondisi dan fungsi manfaat yang digunakan. Sedangkan untuk data peralatan akan dicatat dan diinventarisir sesuai kondisi fisik di gudang. Hasil interview akan dideskripsikan dalam bentuk narasi dan hasil pengamatan lapangan akan dijadikan bahan rancangan tata letak gudang. 


\section{Penarikan kesimpulan}

Hasil penelitian ini berupa data stock opname update, rancangan kartu persediaan, rancangan material dan issue list request, pencatatan peralatan dan rancangan layout gudang di Teknik Perawatan Pesawat Udara, Politeknik Negeri Batam.

\section{Gambar 1: Langkah-langkah Penelitian}

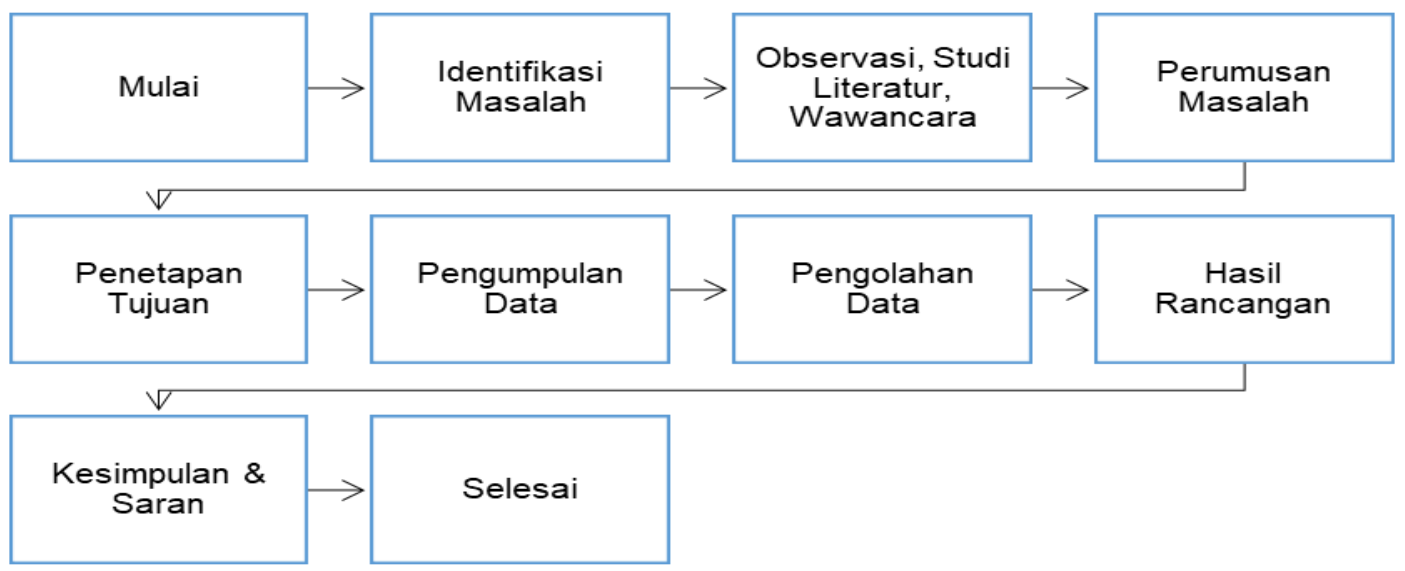

HASIL DAN PEMBAHASAN

Hasil Penelitian

\section{Stock Opname BHP dan Peralatan}

Berikut adalah cuplikan hasil stock opname terbaru untuk persediaan bahan habis pakai dan peralatan di TPPU Politeknik Negeri Batam yang ditampilkan dalam tabel 1:

Tabel 1: Stock Opname BHP

\begin{tabular}{|c|c|c|c|c|c|c|c|}
\hline \multicolumn{8}{|c|}{$\begin{array}{c}\text { TEKNIK PERAWATAN PESAWAT UDARA } \\
\text { BARANG HABIS PAKAI (BHP) }\end{array}$} \\
\hline \multicolumn{8}{|c|}{ Mar-21 } \\
\hline \multirow{2}{*}{ No } & \multirow{2}{*}{ Mata Kuliah } & \multirow{2}{*}{ Nama Barang } & \multirow{2}{*}{ Spesifikasi } & \multirow{2}{*}{ Berat } & \multirow{2}{*}{ Satuan } & \multicolumn{2}{|c|}{ Persediaan Di Gudang } \\
\hline & & & & & & Tanggal & QTY \\
\hline 1 & Control Cable & Wire Cable & Dim 1/16 dan Dim 3/16 (7*19) & & Meter & 03 Maret 2021 & \\
\hline 2 & Riveting & & TP62 & 0.36 & LB & 03 Maret 2021 & 1 \\
\hline 3 & Riveting & Round Head & & \begin{tabular}{lll|}
0,16 & 0,22 & 0,18 \\
\end{tabular} & LB & 03 Maret 2021 & 3 \\
\hline 4 & Riveting & Countersunk & MS20470A4-4 & \begin{tabular}{lllll|}
1 & 1 & 1 & 1,06 & 1,4 \\
\end{tabular} & LB & 03 Maret 2021 & 5 \\
\hline 5 & Riveting & & KEL.ALM3*5KB & $\begin{array}{ll}0,82 & 0,24 \\
\end{array}$ & LB & 03 Maret 2021 & 2 \\
\hline 6 & Riveting & Round Head & AN 430 AD 3-5 & 1.1 & LB & 03 Maret 2021 & 1 \\
\hline 7 & Riveting & & AN470AD-4-5 & $1,06 \quad 2,18 \quad 2,18$ & LB & 03 Maret 2021 & 3 \\
\hline 8 & Riveting & Round Head & AN 430 AD 3-5 & $1,10 \quad 1,10$ & LB & 03 Maret 2021 & 2 \\
\hline 9 & Riveting & & BLIND RIVETS (AS425) SIZE 1/8"*1/4" & 0.78 & LB & 03 Maret 2021 & 1 \\
\hline 10 & Riveting & & AN430AD-4-8 & $2,18 \quad 2,12 \quad 2,12$ & LB & 03 Maret 2021 & 3 \\
\hline 11 & Riveting & & AN426AD-4-8 & 1.64 & LB & 03 Maret 2021 & 1 \\
\hline 12 & Riveting & & AD3-7 & 0.18 & LB & 03 Maret 2021 & 1 \\
\hline 13 & Riveting & & FLAT HEAD RIVET & 0.6 & LB & 03 Maret 2021 & 1 \\
\hline 14 & Riveting & & AN 430 AD 3-7 & 1.16 & LB & 03 Maret 2021 & 1 \\
\hline 15 & Riveting & & AN 435 AD 3-5 & $1 \quad 1,16$ & LB & 03 Maret 2021 & 2 \\
\hline 16 & Riveting & & AN 435 AD 3-7 & 1.08 & LB & 03 Maret 2021 & 1 \\
\hline 17 & Riveting & & $1 / 8 * 1 / 4 * 100 \mathrm{CG} / \mathrm{T}$ & 0.24 & LB & 03 Maret 2021 & 1 \\
\hline 18 & Riveting & & MS20470AD3-4,5 & 0.3 & LB & 03 Maret 2021 & 1 \\
\hline 19 & Riveting & & MS20426AD3-7 & 1.3 & LB & 03 Maret 2021 & 1 \\
\hline 20 & Riveting & & Rivet Solid & 1 & LB & 03 Maret 2021 & 1 \\
\hline 21 & Riveting & & AN426AD-4-5 & 2.2 & LB & 03 Maret 2021 & 1 \\
\hline 22 & Riveting & & Braeicr Head Rivet & 0.46 & LB & 03 Maret 2021 & 1 \\
\hline 23 & General & Kacamata Clear & Clear & & Lusin & 03 Maret 2021 & 2 Lusin $6 \mathrm{pcs}$ \\
\hline 24 & Painting & Respirator Mask & & & Pcs & 03 Maret 2021 & 5 \\
\hline 25 & & Goggles & & & Pcs & 03 Maret 2021 & 11 \\
\hline 26 & Painting & Kuas & & & Pcs & 03 Maret 2021 & 38 \\
\hline 27 & General & Gloves (Speck) & & & Lusin & 03 Maret 2021 & 5 lusin+ 5 pasang \\
\hline 28 & General & Steel Wire Brush & & & Lusin & 03 Maret 2021 & $1 \mathrm{Lusin}+10 \mathrm{pcs}$ \\
\hline 29 & Welding & Kaca Las No 11 & & & Lusin & 03 Maret 2021 & 22 Lusin+4pcs \\
\hline 30 & & Earmuffs & & & Pcs & 03 Maret 2021 & 31 \\
\hline
\end{tabular}

Sumber: Diolah Peneliti, 2021 
Selain stock opname BHP, berikut cuplikan data stock opname inventory untuk checklist toolbox yang ditampilkan dalam tabel 2;

Tabel 2: Update Data Checklist Toolbox

\begin{tabular}{|c|c|c|c|c|c|c|c|c|c|c|c|}
\hline \multicolumn{12}{|c|}{ TEKNIK PERAWATAN PESAWAT UDARA } \\
\hline \multicolumn{12}{|c|}{ CHEKLIST TOOLBOX } \\
\hline \multicolumn{12}{|c|}{ Mar-21 } \\
\hline \multirow{4}{*}{ No } & \multirow{4}{*}{ DESCRIPTION } & \multirow{4}{*}{ PART NUMBER } & & & & & & & & & OUT \\
\hline & & & \multirow{3}{*}{ QTY } & \multicolumn{8}{|c|}{ BOX } \\
\hline & & & & \multicolumn{2}{|c|}{ BOX 4} & \multicolumn{2}{|c|}{ BOX 5} & \multicolumn{2}{|c|}{ BOX 6} & \multicolumn{2}{|c|}{ BO 11} \\
\hline & & & & IN & OUT & IN & OUT & IN & OUT & IN & OUT \\
\hline & Drive Metal-Grip Speed Brace & $\mathrm{J} .115$ & 1 ea & & & & & & & & \\
\hline & Drive Metal-Grip Speed Handle & J.145 & 1 ea & & & & & & & & \\
\hline & 3/8 Drive Sliding Tee & $\mathrm{J} .120 \mathrm{~A}$ & 1 ea & & & & & & & & \\
\hline & 3/8 "Universal Joint & $\mathrm{J} .240 \mathrm{~A}$ & $1 \mathrm{ea}$ & & & & & & & & \\
\hline & Coupler 3/8" To 1/4" & $\mathrm{J} .230$ & $1 \mathrm{ea}$ & & & & & & & & \\
\hline 6 & & J.151A & $1 \mathrm{ea}$ & & & & & & & & \\
\hline 7 & & J.151B & 1 ea & & & & & & & & \\
\hline & Drive Extension $125 \mathrm{~mm}$ & $\mathrm{~J} .210$ & $1 \mathrm{ea}$ & & & & & & & & \\
\hline & 3/8" Drive Long Socket 1/4" & J.1/4 LA & 1 ea & & & & & & & & \\
\hline & 3/8" Drive Long Socket 5/16" & $\mathrm{J} .5 / 16 \mathrm{LA}$ & $1 \mathrm{ea}$ & & & & & & & & \\
\hline & 3/8" Drive Long Socket 3/8" & J.3/8 LA & 1 ea & & & & & & & & \\
\hline & 3/8" Drive Long Socket 7/16" & J.7/16 LA & 1 ea & & & & & & & & \\
\hline & 3/8" Drive Long Socket 1/2" & J.1/2 LA & 1 ea & & & & & & & & \\
\hline & 3/8" Drive Long Socket 9/16" & $\mathrm{J} .9 / 16 \mathrm{LA}$ & 1 ea & & & & & & & & \\
\hline & 3/8" Drive Long Socket 5/8" & J.5/8 LA & 1 ea & & & & & & & & \\
\hline & 3/8" Drive Long Socket 11/16" & J.11/16 LA & $1 \mathrm{ea}$ & & & & & & & & \\
\hline & 3/8" Drive Long Socket 3/4" & $\mathrm{J} .3 / 4 \mathrm{LA}$ & 1 ea & & & & & & & & \\
\hline & 3/8" Drive Long Socket 13/16" & $\mathrm{J} .13 / 16 \mathrm{LA}$ & $1 \mathrm{ea}$ & & & & & & & & \\
\hline & Drive Extension $250 \mathrm{~mm}$ & $\mathrm{~J} .215$ & 1 ea & & & & & & & & \\
\hline & 3/8" Drive Hinged Socket 3/4" & $\mathrm{J} .3 / 4 \mathrm{~F}$ & 1 ea & & & & & & & & \\
\hline & 3/8" Drive Hinged Socket 11/16" & J.11/16F & 1 ea & & & & & & & & \\
\hline & 3/8" Drive Hinged Socket 5/8" & $\mathrm{J} .5 / 8 \mathrm{~F}$ & 1 ea & & & & & & & & \\
\hline & 3/8" Drive Hinged Socket 9/16" & $\mathrm{J} .9 / 16 \mathrm{~F}$ & 1 ea & & & & & & & & \\
\hline & 3/8" Drive Hinged Socket 1/2" & $\mathrm{J} .1 / 2 \mathrm{~F}$ & 1 ea & & & & & & & & \\
\hline & 3/8" Drive Hinged Socket 7/16" & $\mathrm{J} .7 / 16 \mathrm{~F}$ & $1 \mathrm{ea}$ & & & & & & & & \\
\hline & 3/8" Drive Hinged Socket 3/8" & $\mathrm{J} .3 / 8 \mathrm{~F}$ & $1 \mathrm{ea}$ & & & & & & & & \\
\hline
\end{tabular}

Sumber: Diolah Peneliti, 2021

Tabel 3 di bawah ini merupakan cuplikan update data untuk tools atau peralatan yang ada di gudang TPPU Politeknik Negeri Batam;

Tabel 3: Update Data Peralatan

\begin{tabular}{|c|c|c|c|c|c|c|}
\hline \multirow{2}{*}{\multicolumn{7}{|c|}{$\begin{array}{c}\text { TEKNIK PERAWATAN PESAWAT UDARA } \\
\text { TOOLS/PERALATAN }\end{array}$}} \\
\hline & & & & & & \\
\hline & & Mar-21 & & & & \\
\hline & & \multirow{3}{*}{ NAMA BARANG } & \multirow{3}{*}{ SPESIFIKASI } & \multirow{3}{*}{ SATUAN } & & \\
\hline \multirow[t]{2}{*}{ No } & \multirow{2}{*}{ FUNGTION \& TOOLS NAME } & & & & \multicolumn{2}{|c|}{ PERSEDIAAN DI GUDANG } \\
\hline & & & & & $\frac{\text { Tanggal }}{08 \text { Maret } 2021}$ & $\frac{\text { Qty }}{1}$ \\
\hline 2 & \multirow{12}{*}{ Special Tools Equipment } & \begin{tabular}{|l|} 
Cylinder Leakage Tester \\
\end{tabular} & & Set & 08 Maret 2021 & 2 \\
\hline 3 & & Magneto Timing Light & & Barang & 08 Maret 2021 & 2 \\
\hline 4 & & Air Craft Timing Indicator (valve timing) & & Set & 08 Maret 2021 & 1 \\
\hline 5 & & Push Rod Tube Spring Compressor & & Barang & 08 Maret 2021 & 2 \\
\hline 6 & & Piston Pin Removal Tool & & Barang & 08 Maret 2021 & 1 \\
\hline 7 & & \begin{tabular}{|l|} 
Aviation Piston Ring Compressor \\
\end{tabular} & & Set & 08 Maret 2021 & 1 \\
\hline 8 & & ATS Iycoming And Continental Cylinder Base Nut Wrench & & Barang & 08 Maret 2021 & 8 \\
\hline 9 & & Piston Ring Installer & & Barang & 08 Maret 2021 & 1 \\
\hline 10 & & ATS Rocker Shaft Removal Tool & & Barang & 08 Maret 2021 & 1 \\
\hline 11 & & Magneto Overhoul Kit & & Barang & 08 Maret 2021 & 1 \\
\hline 12 & & Magnetic Yoke & & Barang & 08 Maret 2021 & 1 \\
\hline 13 & & Lifting Bar 10 Pounds & & Barang & 08 Maret 2021 & 1 \\
\hline 14 & \multirow{4}{*}{ Micrometer } & Micrometer & M110-50 & Pcs & 08 Maret 2021 & 48 \\
\hline 15 & & Micrometer & M110-25 & Kotak & 08 Maret 2021 & 1 \\
\hline 16 & & \begin{tabular}{|l|} 
Micrometer \\
\end{tabular} & M110-2 & Kotak & 08 Maret 2021 & 1 \\
\hline 17 & & \begin{tabular}{|l|} 
Micrometer \\
\end{tabular} & OM-75 & Kotak & 08 Maret 2021 & 1 \\
\hline 18 & \multirow{2}{*}{ Vernier Caliper } & Vernier Caliper & Besar & Pcs & 08 Maret 2021 & 46 \\
\hline 19 & & Vernier Caliper & Kecil & Pcs & 08 Maret 2021 & 2 \\
\hline 20 & \multirow{2}{*}{ Tensiometer } & Tensiometer & T5-2002-101-00 & Kotak & 08 Maret 2021 & 1 \\
\hline 21 & & Tensiometer & T60 & Kotak & 08 Maret 2021 & 6 \\
\hline
\end{tabular}

Sumber: Diolah Peneliti, 2021 
Tabel 4 di bawah ini merupakan cuplikan data terbaru untuk inventory stock sheet metal dalam Gudang TPPU Politeknik Negeri Batam;

Tabel 4 Inventory Stock Sheet Metal Update

\begin{tabular}{|c|c|c|c|c|c|c|c|}
\hline No & Tools Name & Quantity & $\begin{array}{c}\text { Bag } \\
1 \\
\end{array}$ & $\begin{array}{c}\text { Bag } \\
2 \\
\end{array}$ & $\begin{array}{c}\text { Bag } \\
3 \\
\end{array}$ & $\begin{array}{c}\text { Bag } \\
4 \\
\end{array}$ & $\begin{array}{c}\mathrm{Bag} \\
5\end{array}$ \\
\hline 1 & Rivet Gun & 1 & $\checkmark$ & $\checkmark$ & $V$ & $\checkmark$ & $\checkmark$ \\
\hline 2 & Drill Gun & 1 & $\checkmark$ & $\checkmark$ & $\checkmark$ & $\checkmark$ & $\checkmark$ \\
\hline 3 & Cleco Pilers & 1 & $\checkmark$ & $\checkmark$ & $\checkmark$ & $\checkmark$ & $\checkmark$ \\
\hline 4 & Rivet Cutter & 1 & $\checkmark$ & $\checkmark$ & 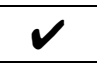 & $\checkmark$ & $\checkmark$ \\
\hline 5 & Bucking Bar & 1 & $\checkmark$ & $\checkmark$ & $\nu$ & $\checkmark$ & $\checkmark$ \\
\hline 6 & $\begin{array}{l}\text { Microstop } \\
\text { Countersink }\end{array}$ & 1 & $\checkmark$ & $\checkmark$ & $\checkmark$ & $\checkmark$ & $\checkmark$ \\
\hline \multirow[b]{2}{*}{7} & River Set & \multirow[b]{2}{*}{1 Set } & \multirow[b]{2}{*}{$\checkmark$} & \multirow[b]{2}{*}{$\checkmark$} & \multirow[b]{2}{*}{$\checkmark$} & \multirow[b]{2}{*}{$\checkmark$} & \multirow[b]{2}{*}{$\checkmark$} \\
\hline & $\begin{array}{l}3 / 32,1 / 8,5 / 32 \\
3 / 16,1^{\prime \prime}\end{array}$ & & & & & & \\
\hline \multirow{2}{*}{8} & Cleco Fastener & \multirow{2}{*}{10} & \multirow{2}{*}{$\checkmark$} & \multirow{2}{*}{$\checkmark$} & \multirow{2}{*}{$\checkmark$} & \multirow{2}{*}{$\checkmark$} & \multirow{2}{*}{$\checkmark$} \\
\hline & $3 / 32,1 / 8,5 / 32,3 / 16$ & & & & & & \\
\hline \multirow{2}{*}{9} & Drill Stop Kit & \multirow{2}{*}{1 Set } & \multirow{2}{*}{$\checkmark$} & \multirow{2}{*}{$\checkmark$} & \multirow{2}{*}{$\boldsymbol{V}$} & \multirow{2}{*}{$\boldsymbol{V}$} & \multirow{2}{*}{$\checkmark$} \\
\hline & \#40 \#30 \#21 \#10 & & & & & & \\
\hline 10 & $\begin{array}{l}\text { Countersink Cutters } \\
21,30,40\end{array}$ & 1 Set & $\checkmark$ & $\boldsymbol{V}$ & $\checkmark$ & $\boldsymbol{V}$ & $\boldsymbol{V}$ \\
\hline
\end{tabular}

Sumber: Diolah Peneliti, 2021

\section{Rancangan Inventory Stock}

Di bawah ini merupakan rancangan inventory stock untuk persediaan habis pakai dan peralatan di TPPU Politeknik Negeri Batam:

Tabel 5: Rancangan Inventory Stcok

\begin{tabular}{|c|c|c|c|c|c|c|c|c|c|c|c|c|c|c|c|}
\hline \multicolumn{16}{|c|}{ KARTU PERSEDIAAN BAHAN HABIS PAKAI (BHP) } \\
\hline \multirow{4}{*}{\multicolumn{2}{|c|}{$\begin{array}{l}\text { TEMPAT : } \\
\text { INSTANSI : } \\
\text { KOTA } \\
\text { PROVINSI : }\end{array}$}} & \multirow{2}{*}{\multicolumn{3}{|c|}{$\begin{array}{l}: \text { TEKNIK PERAWA TAN PESAWAT UDARA (TPPU) } \\
\text { : POLITEKNIK NEGERI BA TAM }\end{array}$}} & & & & & & & & & & & \\
\hline & & & & & \multicolumn{11}{|c|}{ : POLITEKNIK NEGERI BATAM } \\
\hline & & \multicolumn{14}{|c|}{ : BATAM } \\
\hline & & \multicolumn{14}{|c|}{ : KEPULAUAN RIAU } \\
\hline \multirow[t]{2}{*}{$\begin{array}{l}\mathrm{N} \\
\mathrm{O}\end{array}$} & \multirow[t]{2}{*}{$\begin{array}{l}\text { Tanggal } \\
\text { Penerimaan }\end{array}$} & \multirow[t]{2}{*}{$\begin{array}{c}\text { Tanggal } \\
\text { Pengeluaran }\end{array}$} & \multirow[t]{2}{*}{ Mata Kuliah } & \multirow[t]{2}{*}{$\begin{array}{l}\text { Nama } \\
\text { Barang }\end{array}$} & \multirow[t]{2}{*}{ Spesifikasi } & \multirow[t]{2}{*}{$\begin{array}{c}\text { Satua } \\
n\end{array}$} & \multirow[t]{2}{*}{$\begin{array}{l}\text { Tanggal } \\
\text { Persediaan di } \\
\text { Gudang }\end{array}$} & \multicolumn{3}{|c|}{ Barang - Barang } & \multirow[t]{2}{*}{$\begin{array}{l}\text { Harga } \\
\text { Satua } \\
\text { n }\end{array}$} & \multicolumn{3}{|c|}{$\begin{array}{l}\text { Jumlah Harga Barang yang } \\
\text { diterima dikeluarkan Sisa }\end{array}$} & \multirow[t]{2}{*}{ Keterangan } \\
\hline & & & & & & & & Masuk & Keluar & $\begin{array}{l}\text { Sisa } \\
\text { lQty }\end{array}$ & & $\begin{array}{l}\text { Berta } \\
\text { mbah }\end{array}$ & Berkurang & Sisa & \\
\hline 1 & & & Control Cable & Wire Cable & $\begin{array}{c}\operatorname{Dim} 1 / 16 \operatorname{dan} \\
\operatorname{Dim} 3 / 16 \\
\left(7^{*} 19\right) \\
\end{array}$ & Meter & 03 Maret 2021 & & & & & & & & \\
\hline \multirow{8}{*}{2} & & & \multirow{8}{*}{ Riveting } & & TP62 & LB & 03 Maret 2021 & 1 & & 1 & & & & & \\
\hline & & & & Round Head & & LB & 03 Maret 2021 & & & 3 & & & & & \\
\hline & & & & Countersunk & MS20470A4-4 & LB & 03 Maret 2021 & & & 5 & & & & & \\
\hline & & & & & $\begin{array}{c}\text { KEL.ALM3 } \\
\text { KB }\end{array}$ & LB & 03 Maret 2021 & & & 2 & & & & & \\
\hline & & & & Round Head & AN 430 AD $3-5$ & LB & 03 Maret 2021 & & & 1 & & & & & \\
\hline & & & & & AN470AD-4-5 & LB & 03 Maret 2021 & & & 3 & & & & & \\
\hline & & & & Round Head & AN 430 AD 3-5 & LB & 03 Maret 2021 & & & 2 & & & & & \\
\hline & & & & & $\begin{array}{c}\text { BLIND } \\
\text { RIVETS } \\
\text { (AS425) SIZE }\end{array}$ & LB & 03 Maret 2021 & & & 1 & & & & & \\
\hline
\end{tabular}

Sumber: Diolah Peneliti, 2021 


\section{Rancangan Material Issues List}

Di bawah ini merupakan rancangan material issues list untuk persediaan habis pakai dan peralatan di TPPU Politeknik Negeri Batam;

Tabel 6: Rancangan Material Issues List

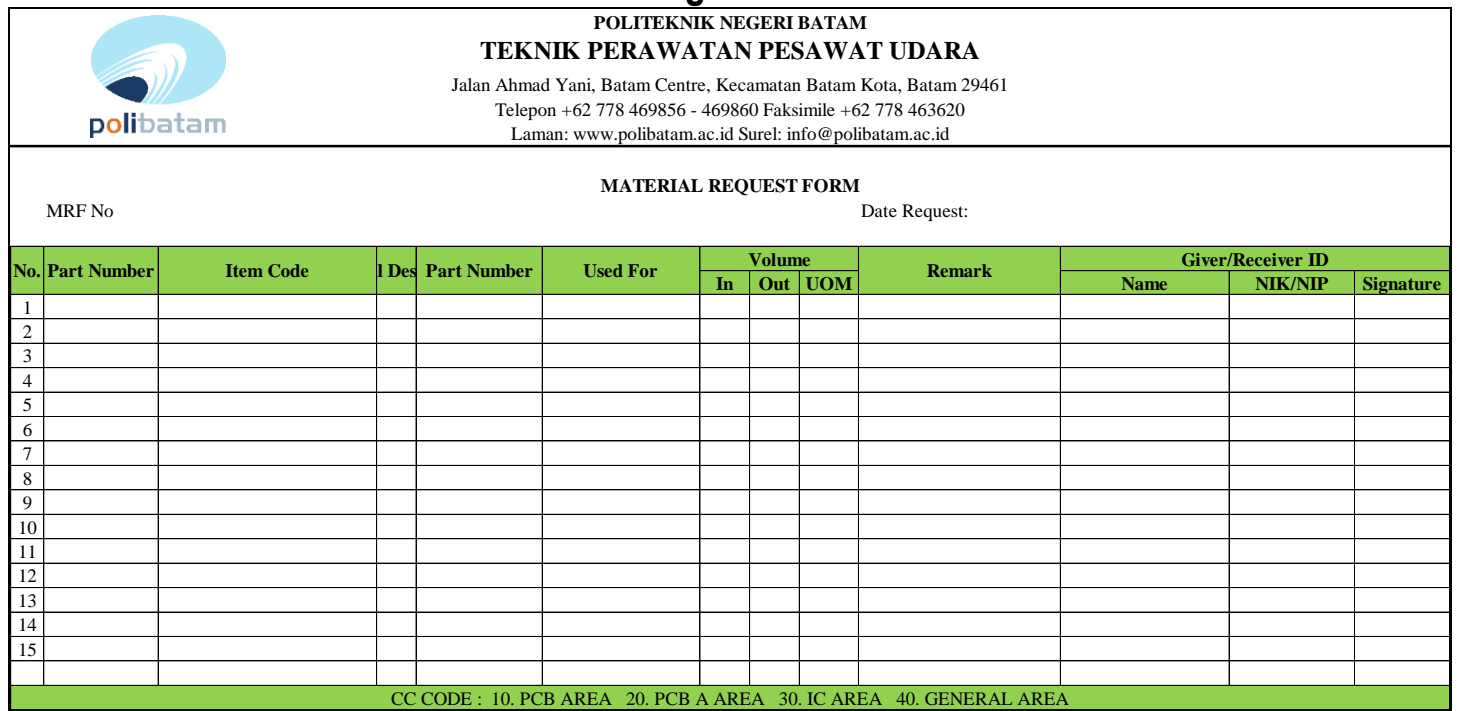

Sumber: Diolah Peneliti, 2021

\section{Rancangan Material Request Form}

Dibawah ini merupakan rancangan material request form untuk persediaan habis pakai dan peralatan di TPPU Politeknik Negeri Batam;

Tabel 7: Rancangan Material Request Form

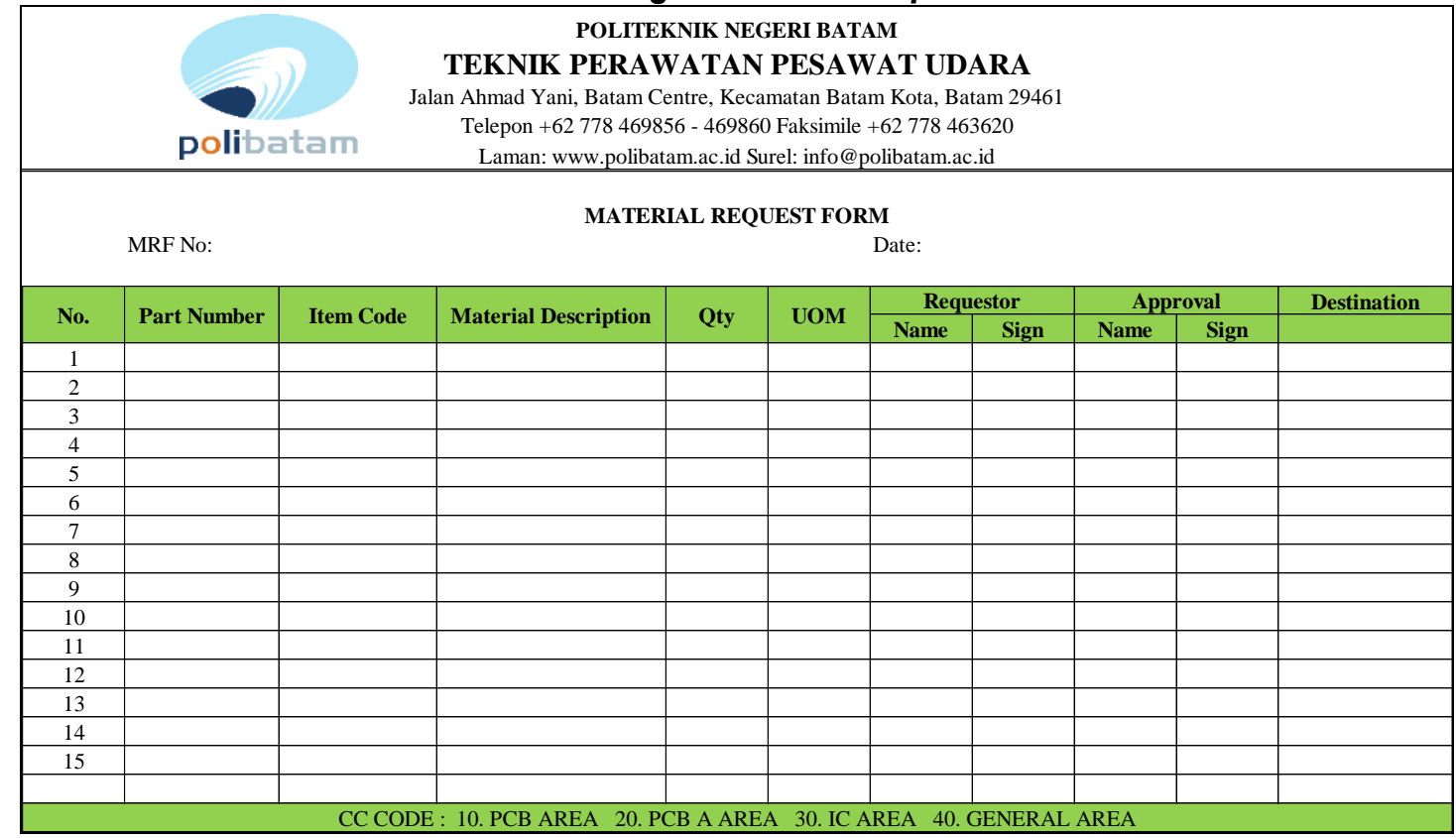

Sumber: Diolah Peneliti, 2021 


\section{Rancangan Layout Gudang}

Adapun tahapan dan urutan proses untuk merancang layout gudang yang dilakukan sebagai berikut:

1. Pertama tahap pendahuluan, yaitu pengamatan awal mengenai permasalahan utama di lapangan hingga diperoleh pendefinisian awal mengenai permasalahan yang diangkat serta melakukan studi tentang hal-hal yang terkait dengan tata letak gudang.

2. Kedua adalah tahap pengumpulan dan pengolahan data. Pada tahap ini dilakukan pengumpulan data yang mendukung dalam proses penelitian mengenai tata letak gudang bahan habis pakai, diantaranya data tata letak gudang existing meliputi luas dan tinggi gudang, alat-alat yang terdapat di gudang bahan baku beserta dimensinya.

3. Tahap ketiga adalah analisa terhadap tata letak gudang bahan habis memakai usulan yang telah diperoleh dengan kebijakan penempatan yang baru berdasarkan metode class-based storage serta tata letak fasilitas yang ada di gudang bahan habis pakai. Sehingga dapat memperlancar proses yang terdapat di gudang bahan habis pakai dan peningkatan kapasitas gudang. Dengan kebijakan penempatan class-based storage, bahan habis pakai dikelompokkan berdasarkan jenisnya dan diurutkan menurut jumlah permintaannya. Peralatan dengan permintaan terbesar diletakkan paling dekat dengan pintu keluar masuk, sehingga mempercepat bahan habis pakai karena tidak perlu mencari ke seluruh gudang, melainkan cukup mencari pada rak yang telah ditempatkan

Adapun tata letak gudang bahan habis pakai yang digambarkan dengan 2 dimensi, yaitu: 


\section{Gambar 2: Gudang Awalan 2 dan 3 Dimensi}

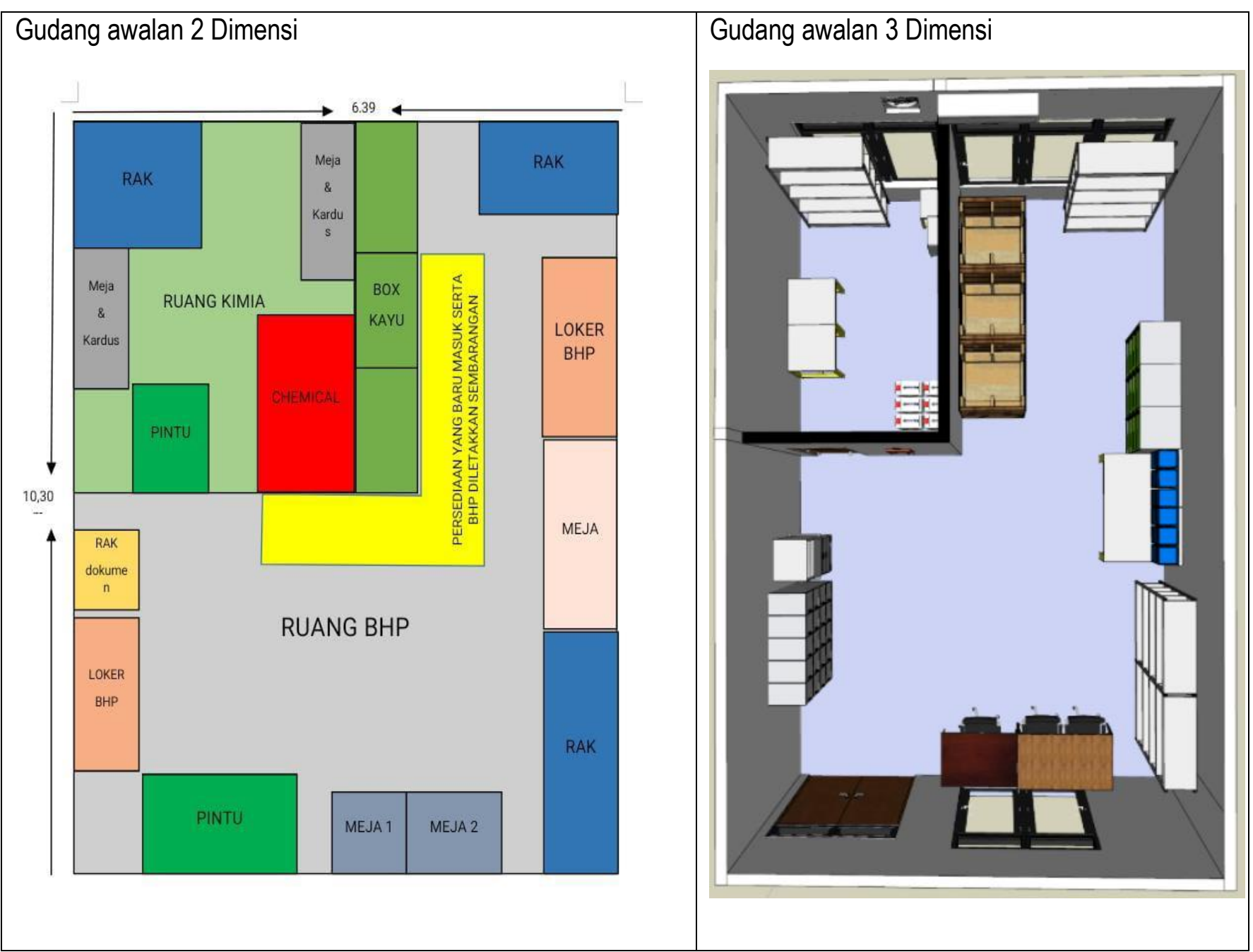

Sumber: Diolah Peneliti, 2021

\section{Uraian Rencana, Pelaksanaan dan Implementasi}

1. Rencana Implementasi

Rencana implementasi usulan tata letak gudang akan dilaksanakan pada Gudang Bahan Habis Pakai (BHP) di ruangan Tempat Perawatan Pesawat (TPPU) Politeknik Negeri Batam. Implementasi usulan ini akan dilaksanakan apabila mendapatkan persetujuan dari TPPU maupun pihak-pihak lainnya yang bersangkutan. Untuk mendapatkan persetujuan tersebut, penulis telah melakukan usulan perbaikan agar kedepan layout gudang semakin baik, sehingga peralatan atau barang mudah dicari. Usulan yang penulis berikan tidak hanya bertujuan untuk memudahkan dalam mencari peralatan yang diinginkan, tetapi usulan yang penulis berikan juga memberikan manfaat seperti mengurangi kecelakaan kerja yang tidak diinginkan. 
Gambar 3: Rancangan Layout Gudang

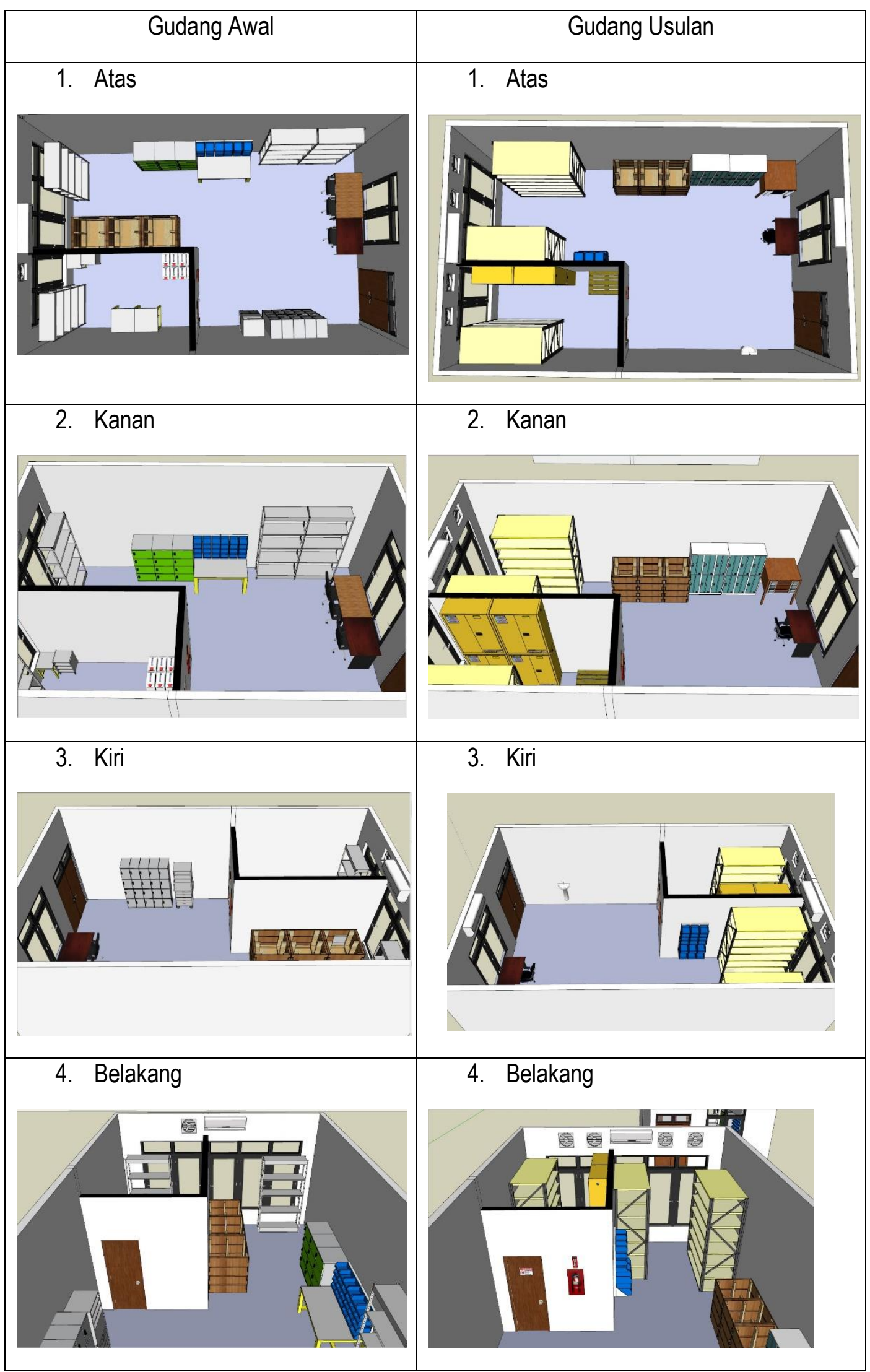




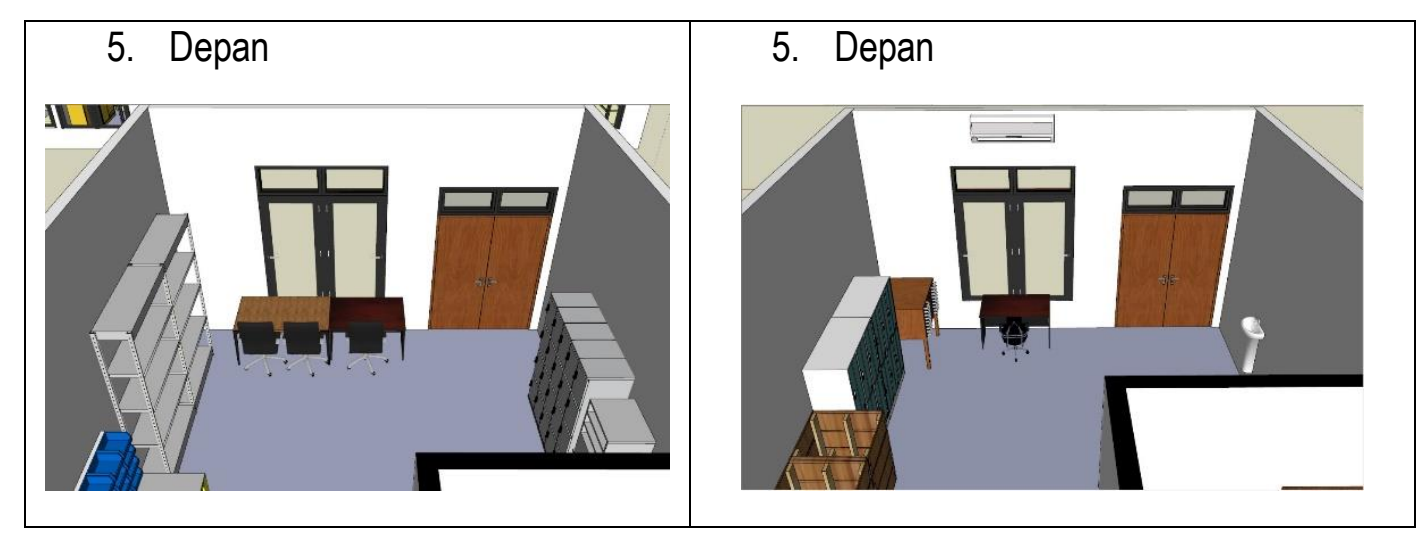

Sumber: Diolah Peneliti, 2021

2. Pelaksanaan Implementasi

Pelaksanaan yang akan dilakukan sesuai dengan usulan-usulan yang telah penulis berikan, yaitu:

a) Menambah beberapa rak

b) Mengklasifikasikan barang menjadi tiga bagian yaitu bahan habis pakai, hasil kerajinan mahasiswa, dan bahan kimia.

c) Mengeluarkan meja dan kursi yang tidak diperlukan

d) Mengeluarkan kardus - kardus yang tidak diperlukan lagi

e) Mengatur tata letak rak

f) Memindahkan posisi Smoke Detector yang ada digudang utama ke gudang kimia,

g) Menambah sekat pada box yang berisikan bahan habis praktikum

h) Menambahkan APAR

i) Menambahkan Wastafel

j) Memberikan Simbol pada pintu ruang kimia

3. Efektifitas Pelaksanaan Implementasi

Pelaksanaan Implementasi akan efektif apabila dilakukan sesuai dengan prosedur/ketentuan yang telah ditetapkan. Misalnya bentuk rak maupun loker sesuai dengan usulan yang diberikan, menambahkan appar dan wastafel untuk menghindari kecelakaan kerja serta mengubah peletakan smoke detector yang awalnya berada di ruangan umum dipindahkan ke ruangan kimia, dikarenakan tingkat kebakaran pada ruang kimia lebih tinggi dari pada ruang umum.

4. Tantangan dalam Implementasi

Tantangan dalam implementasi tata letak gudang usulan yang penulis berikan yaitu biaya. Pihak-pihak yang bersangkutan akan mengeluarkan biaya untuk membeli peralatan, seperti pembelian appar, wastafel, serta lemari B3 penyimpanan bahan yang mudah terbakar. Penulis tidak bisa memprediksi apakah pelaksaan implementasi usulan gudang ini dapat efektif atau tidak saat melakukan perbaikan tata letak gudang, dikarenakan belum dilakukannya perbaikan gudang dan penulis hanya melakukan usulan saja. Penulis berharap usulan yang diberikan dapat diterima dan diterapkan oleh pihak-pihak yang bersangkutan. 


\section{REKOMENDASI KEBIJAKAN}

\section{Rekomendasi}

Berdasarkan hasil pembahasan pada BAB sebelumnya, maka dapat penulis rekomendasikan hasil penelitian bahwa;

1. Pengelolaan persediaan bahan habis pakai pada Program Studi Teknik Perawatan Pesawat Udara (TPPU) Politeknik Negeri Batam telah dilakukan, dimana langkah pertama adalah stock opname update, pencatatan BHP ke dalam Microsoft Excel, memberikan rancangan untuk material request form, Issue request list dan rancangan inventory stock.

2. Selain persediaan bahan habis pakai, inventarisir tools atau peralatan praktikum di Gudang TPPU juga telah dilakukan, dimana langkah pertama adalah stock opname update khusus tools, pencatatan di Microsoft Excel serta inventarisir peralatan sesuai box, memberikan rancangan material request form dan issue request list.

3. Rancangan Layout atau tata letak gudang bahan habis telah dilakukan dengan menggunakan metode class-based storage serta tata letak fasilitas yang ada di gudang BHP TPPU Politeknik Negeri Batam

\section{Kebijakan}

Berdasarkan hasil pengamatan dan hasil penelitian, saran yang dapat penulis berikan adalah

1. Bagi Manajemen TPPU Politeknik Negeri Batam

a. Selalu melakukan stock opname secara rutin untuk menghindari kesalahan pencatatan dan fisik barang di Gudang

b. Menambah pegawai untuk mengelola administrasi persediaan dan pergudangan baik di Gudang BHP, tools dan produk hasil praktikum

c. Menyusun SOP untuk pengelolaan persediaan BHP dan peralatan

d. Menambah fasilitas di gudang sesuai saran pada BAB IV untuk tata letak gudang sehingga layout gudang akan semakin baik dan aman bagi penggunanya

2. Bagi penulis selanjutnya

a. Melakukan usulan rancangan tahapan selanjutnya yaitu perbaikan pencatatan produk hasil praktikum, perancangan sistem persediaan BHP dan peralatan, merancang penyusunan SOP pengelolaan persediaan BHP dan peralatan.

b. Melakukan penelitian kolaborasi antara Program Studi Akuntansi dan Program Studi Multimedia Jaringan serta Prodi Informatika untuk merancang sistem persediaan dan peralatan

\section{DAFTAR PUSTAKA}

Malhotra, 2007. Marketing Research an Applied Orientation. International Edition: Pearson

Martani, D., Veronica, S., Wardhani, R., Farahmita, A., \& Tanujaya, E. (2016). Akuntansi Keuangan Menengah (E. S. Suharsi (ed.); kedua). Salemba Empat.

Purwaji, A., Wibowo, \& Lestari, H. S. (2016). Pengantar Akuntansi 2 (I. Khasanah (ed.); 2nd ed.). Salemba Empat.

Romadhon, N. I. (2021). Analisis Persediaan Barang Habis Pakai dengan Menggunakan Metode Min-Max di Universitas Pertamina (Doctoral dissertation)

Tyoso, J. S. P. (2016). Sistem Informasi Manajemen. Deepublish. 
Titu, M. A. (2015). Penerapan model pembelajaran project-based learning ( $\mathrm{PjBL}$ ) untuk meningkatkan kreativitas siswa pada materi konsep masalah ekonomi. In Prosiding Seminar Nasional (Vol. 9).

Wahyudin, D. (2020). Perbaikan Tata Letak Gudang 1 Barang Jadi Dengan Menggunakan Metode Dedicated Storage (Studi Kasus: PT. Garam Segoromadu) (Doctoral dissertation, Universitas Muhammadiyah Malang). 